\title{
Development and Validation of a Culturally-Tailored Breast Cancer Health Education Programme for Arab Women
}

"Esra Alkhasawneh, ${ }^{1}$ Yahya Al-Farsi, ${ }^{2}$ Fayez Al-Simadi, ${ }^{3}$ Michael Leocadio ${ }^{4}$

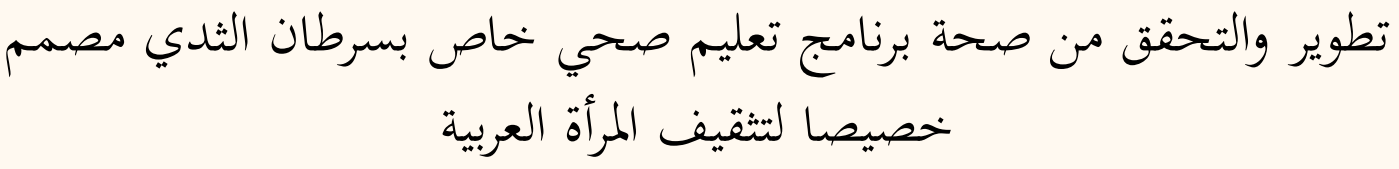

إسراء منصور الخصاونة، يحيى الفارسي، فايز الصمادي، مايكل ليوكاديو

ABSTRACT: Objectives: This study aimed to develop and validate a health education programme to encourage breast cancer awareness and early detection behaviours among Arab women. Methods: This study took place between December 2015 and March 2016. The Enabling Systems Raising Awareness model was used to develop a breast cancer health education programme which was subsequently implemented by trained health educators at three female-only fitness clubs in Muscat, Oman. Breast cancer knowledge among 53 women was assessed using the breast module of the Cancer Awareness Measure before and after each health education session. Overall pre- and post-session knowledge scores were then compared. Additionally, three focus group discussions were conducted with 10 participants from each location. Thematic analysis was used to analyse the transcribed discussions and collect feedback on the programme. Results: The health education sessions resulted in a statistically significant increase in overall mean knowledge scores $(P<0.001)$. Participants also reported significantly improved intentions to undertake early detection practices $(P<0.001)$. The focus group discussions yielded distinct themes and valuable feedback which can be utilised in the future to create an improved version of the programme. Conclusion: While the health education programme significantly improved breast cancer and early detection knowledge among a cohort of Arab women, it still required critical improvements in terms of structure and administration. Additional studies are required in order to evaluate long-term behavioural outcomes resulting from the improved programme.

Keywords: Breast Cancer; Preventive Health Services; Health Behavior; Health Education; Health Promotion; Validation Studies; Oman.

الهلخص: الههف: هدفت هذه الدراسة إلى تطوير برنامج التثقيف الصحي والتحقق من صحته من أجل رفع الوعي بسرطان الثدي وسلوك

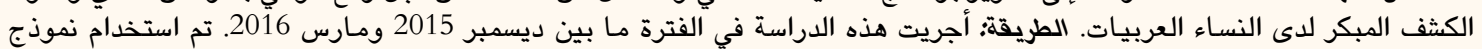

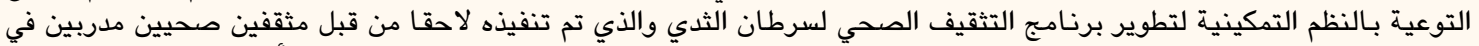

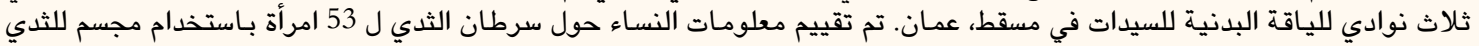

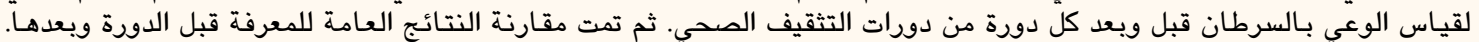

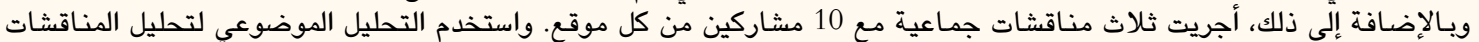

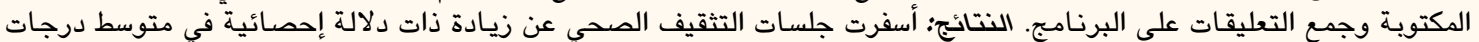

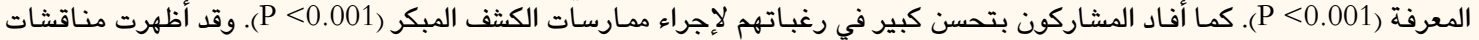

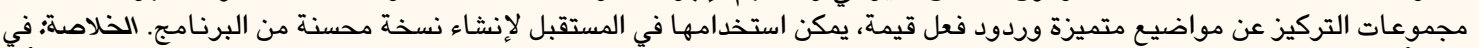

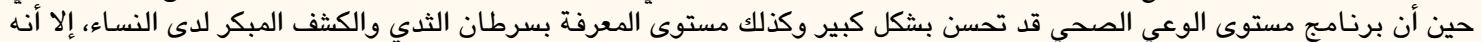

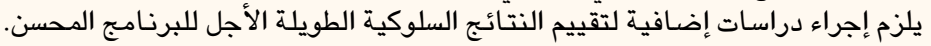

الكلمات المفتاحية: سرطان الثدي؛ الخدمات الصحية الوقائية؛ التصرف الصحي؛ التثقيف الصحي؛ التوعية الصحية؛ دراسات تحقيقية؛ عمان.

\footnotetext{
AdVANCES IN KNOWLEDGE

This study developed and validated a breast cancer health education programme for use among Arab women.

The health education programme significantly improved overall knowledge of breast cancer risk factors, symptoms and early detection methods among a cohort of Omani women.

The findings of this study resulted in valuable qualitative feedback to be used in the development of an improved version of the programme; this improved version could then potentially be implemented nationwide in Oman.
}

\section{Application to Patient Care}

Enhanced awareness of breast health among Omani women may help to improve early detection of breast cancer and the use of early detection services such as mammography. 
$\mathrm{B}$ REAST CANCER IS THE MOST COMMON CAUSE of cancer-related deaths among women worldwide. ${ }^{1}$ In addition, the burden of breast cancer is higher in less developed countries, constituting $58-65 \%$ of all breast cancer-related deaths. ${ }^{1,2}$ In Oman, women are diagnosed with breast cancer at a younger age and at a more advanced stage compared to developed countries. ${ }^{3,4}$ Nevertheless, breast cancer awareness remains low in Arab societies, mostly due to fear, modesty, lack of health education, limited access to breast health services and common misconceptions. ${ }^{3,5}$ In terms of awareness, Omani women show similar characteristics in comparison to those from other Arab countries, such as Qatar, Saudi Arabia and Jordan. ${ }^{6-10}$ A previous qualitative study has highlighted various factors that influence breast cancer awareness among Omani women and the desire among this population for enhanced breast cancer information systems and programmes. ${ }^{6}$

Various studies have recognised the need for breast cancer health education programmes. ${ }^{11-15}$ However, it is necessary to address barriers to breast cancer awareness and early detection in the context of the local population's presiding social and cultural beliefs. ${ }^{9,10,16,17}$ Health education interventions therefore need to be culturally and linguistically tailored, while still portraying breast cancer as a treatable disease. ${ }^{14,18-20}$ Learning strategies, activities and tools should also be aligned with the local cultural context. ${ }^{21,22}$ In Bangladesh, China, Saudi Arabia, Egypt and Iran, health education campaigns have resulted in a significant positive impact on breast cancer awareness levels and early detection practices, with improved awareness, positive health beliefs and increased early detection activities and suitable follow-up practices after abnormal examination results. ${ }^{12,23-26}$

The Enabling Systems Raising Awareness (ESRA) model is based on the following four premises: (1) that individuals can actively regulate their own behaviours; (2) that they interact with the environment on multiple biopsychosocial levels, eventually shaping and being shaped by the environment over time; (3) that health practitioners greatly affect individuals by exerting influence on them; and (4) that self-initiated reconstruction or empowerment of person-environment interactive patterns is essential to change behaviours. ${ }^{6,27}$ Additionally, the ESRA model emphasises specific systems which either enable or inhibit Arab women in terms of health awareness. According to modifiability, these include personal (e.g. cultural, religious or fatalistic beliefs), interpersonal (e.g. familial or environmental factors) and healthcare-related systems [Table 1]. ${ }^{6}$ Furthermore, the model highlights the complete influence of external enabling systems on each other, known as the "pouring-in" process, while the influence of Omani women across systems to initiate interventions to increase awareness is an "out-pouring" process (i.e. an empowering internal enabling system). As such, each Arab woman is considered an instrument or enabler for other women in the advocacy for breast cancer awareness [Figure 1]. ${ }^{6}$ This framework therefore suggests a sustainable method of improving breast cancer awareness in Arab countries, in that public health programmes can use existing enabling systems to improve awareness levels among groups of women, after which empowered women can then spread their knowledge to other women, resulting in a multiplier effect.

This study aimed to develop and validate a breast cancer health education programme for Arab women based on the ESRA model. ${ }^{6}$ An asset-mapping exercise prior to development of the programme did not identify any existing formal or standardised breast health programmes that had been previously implemented in Oman. It is hoped that the findings of this study will enable public health practitioners,

Table 1: Systems, concepts and relevant content objectives of the Enabling Systems of Raising Awareness breast cancer model ${ }^{6}$

\begin{tabular}{|c|c|c|}
\hline System & Concepts & Content objectives \\
\hline Cultural/religious/fatalistic & $\begin{array}{l}\text {-Self-empowerment by addressing } \\
\text { sociocultural factors seen as facilitators/ } \\
\text { barriers to breast cancer awareness } \\
\text {-Cancer fatalism }\end{array}$ & $\begin{array}{l}\text {-Encourage familiarity and comfort with breast self- } \\
\text { examination, i.e. "knowing your own breasts" } \\
\text {-Stress that breast cancer can be cured if detected early } \\
\text { and that a diagnosis of breast cancer is not a death } \\
\text { sentence }\end{array}$ \\
\hline Personal/familial/environmental & $\begin{array}{l}\text {-Social stigma/taboos associated with breast } \\
\text { cancer }\end{array}$ & $\begin{array}{l}\text { - Highlight the importance of breast cancer awareness in } \\
\text { family and society } \\
\text {-Encourage awareness of breast cancer risk factors, signs } \\
\text { and symptoms } \\
\text { - Stress the importance of taking immediate and } \\
\text { appropriate action when the risk of breast cancer is high } \\
\text {-Emphasise the prioritisation of one's own health }\end{array}$ \\
\hline Healthcare-related & $\begin{array}{l}\text {-Familiarity with early detection and medical } \\
\text { resources } \\
\text {-Availability of local resources } \\
\text {-Accessibility of local resources }\end{array}$ & $\begin{array}{l}\text {-Describe the different forms of early detection practices } \\
\text {-Disclose provisions for breast health and early detection } \\
\text { in the local healthcare system }\end{array}$ \\
\hline
\end{tabular}




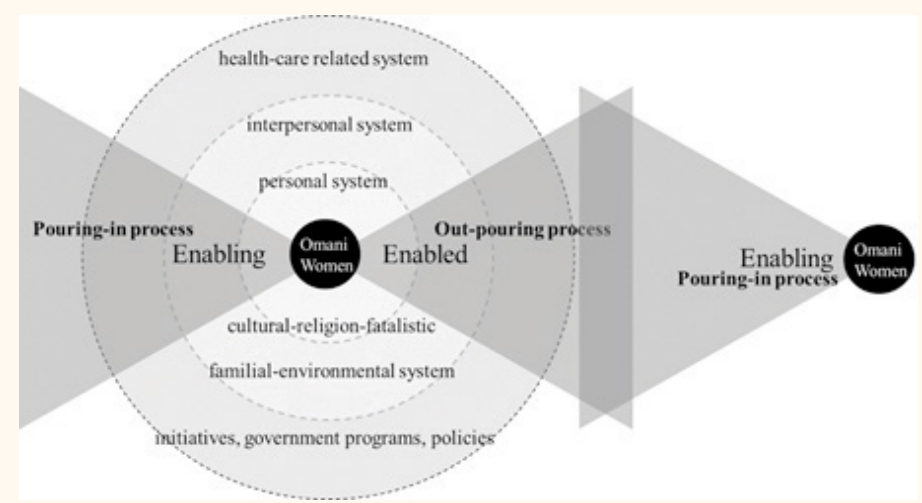

Figure 1: Diagram of the Enabling Systems of Raising Awareness (ESRA) breast cancer model. Note the increasing modifiability of the factors moving closer towards the centre of the model.

Reproduced with permission from Alkhasawneh E, Siddiqui ST, Leocadio M, Seshan V, Al-Farsi Y, Al-Moundhri MS. I do not even say "it": A mixed methods study on breast cancer awareness of Omani women. ${ }^{6}$

health professionals and policy-makers in Oman to better understand the role of health education in breast cancer awareness and early detection. In addition, the results of this study may guide similar health education models for future breast cancer-related programmes in Arab populations.

\section{Methods}

This study took place between December 2015 and March 2016. Based on the previously described ESRA model, a breast cancer health education programme was developed in both Arabic and English. ${ }^{6}$ Primary and secondary research was conducted on breast cancer education programmes and barriers to breast cancer awareness and early detection among Omani women. Three academics from Sultan Qaboos University (SQU), Muscat, Oman, and the University of Jordan (UJ), Amman, Jordan, who were familiar with breast cancer awareness programmes were consulted. Focus group discussions were held with Omani women recruited from three female-only fitness clubs regarding local factors that influence breast cancer awareness and early detection levels. In addition, four health professionals were interviewed regarding breast cancer screening and diagnosis services at local health facilities. All content, materials, learning strategies and evaluation techniques utilised in the programme were designed in consultation with these experts. A literature review was undertaken of previously published evidence-based breast cancer health education programmes and recent studies assessing breast cancer awareness levels among Arab women. $3,4,6,28,29$

The development of the programme was an iterative process, leading to multiple versions of the programme until the final version was ready for implementation. The content was reviewed to improve its linguistic and cultural sensitivity as well as the visual design, content, flow of ideas and structure of the programme. In particular, the health education programme was designed to desensitise the notion of examining/touching breasts by emphasising that breasts are an important part of the body and should be treated with the same respect as other body parts. As all breasts are different, it was necessary to stress the importance of "knowing your own breasts" so that each woman would be able to recognise any potential abnormalities, for instance by noting changes in the appearance or texture of their breasts. The health education programme was also designed to be as interactive as possible. Each section started with a few open-ended questions to initiate discussion, followed by information to be shared by the health educator. An effective learning activity called the 'myth and fact game' was developed, which aimed to dispel common local misconceptions such as "breast cancer cannot be treated", "breast cancer is always painful", "a small lump in your breast can be ignored" and "the evil eye is a risk factor for breast cancer". 6

The content of the programme was designed to be understandable to a layperson with no prior medical knowledge and included breast cancer statistics (e.g. incidence rates) and knowledge regarding the definition of the disease, specific diseases stage, risk factors, signs/symptoms, early detection practices and treatments [Table 2]. Each section of the programme used specific learning strategies that suited the topic being discussed. Some sections were explained using pictographs, as facts presented with pictures are not only easily understandable but also better retained. ${ }^{30}$ Cultural, religious or fatalistic beliefs and interpersonal or familial factors affecting breast health were addressed during an open discussion, as these topics required more in-depth interaction with the participants. Images and a breast model were used 
Table 2: Outline of a breast cancer health education programme for Arab women based on the Enabling Systems of Raising Awareness breast cancer model ${ }^{6}$

Learning objective
Clarify the incidence of breast cancer
and associated risk factors among
Omani women
Correct personal beliefs or local
misconceptions related to breast
cancer and discuss fatalism and
breast cancer with regards to Islamic
teachings

Identify challenges to breast health

Enumerate the signs and symptoms of breast cancer and possible results of non-action

List possible early detection practices

Describe different ways to promote breast health

Encourage participants to sign a motivational contract to promote breast health as positive reinforcement

\section{Content}

-What is breast cancer and how does it affect you, your family and society?

-What can you do about it?

-Which of the following statements about breast cancer are true and which are false?

-What are some of the other breast cancer-related

risk factors or facts that you have heard of?

-How do you think women get breast cancer? Can

you change your fate of getting breast cancer? Can

you take action towards maintaining your own health?

-What are the issues that women face in looking after their breast health?

- Have you personally faced any of these?

-What would you do in these situations?

- How might women take proactive measures towards maintaining their breast health?

-How can you tell if you might have a tumour? -What are the signs and symptoms of breast cancer?

-How can you detect breast cancer early?

-Where can you go to have your breasts examined?

-Did you know that mammography services are available at tertiary hospitals? Have you heard of the

Oman Cancer Association? Did you know there is

a walk-in breast cancer clinic at the Sultan Qaboos

University Hospital?

-What are some of the things you can do to improve your overall health?

- Should we take a pledge of commitment towards breast health?

\section{Learning strategy}

-Multimedia presentation -Short discussion

- "Myth or fact" game

-Multimedia presentation

-Short discussion

-Discussion of challenges factors

-Multimedia presentation

-Short discussion

-Multimedia presentation

-Short discussion

-Discussion of healthy habits

- Recitation of pledge in unison -Signing of pledge to demonstrate the appearance and texture of breast changes. In line with the ESRA model, the health education programme ended with the participants taking part in a vocal and signed pledge to prioritise their breast health and promote breast cancer awareness at the personal, familial and community levels. ${ }^{6}$ The entire programme was designed to be delivered via a printed handout with an accompanying multimedia PowerPoint presentation, Version 2010 (Microsoft Corp., Redmond, Washington, USA).

Four Omani nursing students were trained to deliver the health education programme using a training manual developed by the research team. These trainee health educators were bilingual in Arabic and English and their nationality ensured that cultural sensitivity was maintained. The trainee health educators underwent 10 hours of training on the content of the programme, the research method being used, research ethics, various strategies and activities for delivering the programme and effective public speaking skills. The final training session included rehearsals and role-playing exercises to gauge the effectiveness of the training, ensure standardised delivery of the programme and simulate potential issues and questions. Rehearsals were attended by the research team, an oncologist and nursing faculty members specialising in community health. The attendees included both Arabic speakers to judge content delivery and non-Arabic speakers to judge body language and the method of delivery. During the final training session, the trainee health educators were explicitly instructed to avoid behaviours that could influence the results of the study, including providing additional explanations or clarifications not included in the content of the programme.

Four health education sessions using the programme were conducted by the trained health educators over a one-week period in February 2016 at three female-only fitness clubs in Muscat. The sessions were advertised several days beforehand via social media, text messages and posters. The sessions were open to all women regardless of their membership to the fitness club. Each session was conducted at the publicised time by two of the trained health educators. Women already present at the location at the time of each session were invited to participate in upcoming sessions. As the sample size for each session needed to be manageable for subsequent discussion groups 
while also sufficient for pre- and post-test quantitative evaluation of the programme, up to 15 women were recruited for each session via a convenience sampling method. ${ }^{6,10}$ Women $\leq 20$ years old were included in the study due to the relatively high incidence of young women being diagnosed with breast cancer in Oman. ${ }^{3,4}$ A convenience sampling technique was used to find willing participants who were easily accessible and to minimise the attrition rate between pre- and postsession surveys. During the session, each participant was provided with a structured handout to record information on breast cancer signs and symptoms, risk factors and early detection practices.

A previously translated and adapted Arabic version of the breast module of the Cancer Awareness Measure (BCAM) was used to determine the effectiveness of the programme as an interventional tool for improving breast cancer awareness and early detection practices. ${ }^{31,32}$ The BCAM tool assesses awareness of breast cancer risk factors, signs and symptoms as well as knowledge and intentions regarding early detection practices. ${ }^{31}$ The modified translated survey has shown acceptable reliability and internal consistency (Cronbach's alpha values of 0.856 and 0.890 for the risk factors and warning signs subscales, respectively). ${ }^{32}$ The modified translated BCAM survey was distributed before and after each health education session. In addition, demographic information such as age, marital status, education and income level was recorded. Participants were requested not to discuss the survey questions among themselves and the health educators stressed the importance of completing both the pre- and post-session surveys. If a participant was unable to read Arabic or English, the trained health educators read the questions to them out loud in private and asked the participant to answer using one of the multiple-choice responses. Before the end of the session, the participants were informed that they might be invited at a later date to take part in focus group discussions in order to provide feedback on the sessions. Each session was audio-recorded by one of the health educators and an accompanying research assistant. Feedback on the session was analysed by the research team and the three academic experts from SQU and UJ during post-session debriefing meetings with the health educators.

Following this, focus group discussions were conducted in Arabic at each of the three fitness centres with groups of 10 women from each centre. Participants were randomly selected from the signup sheets of those who had previously taken part in the health education sessions. Two research assistants were trained to conduct the discussions, with one actively moderating the discussion and the other recording important observations and comments. The discussions focused on the organisation, time management, setting, content, flow, clarity, teaching style and delivery of the sessions. In addition, the participants were encouraged to voice their questions and concerns, remark on any unanswered questions and discuss the availability of information and resources about breast health in Oman. Each discussion was audio-recorded, transcribed and translated into English for qualitative analysis. However, the transcripts of the discussions were initially prepared in Arabic in order to improve the reliability of the feedback and to ensure that no information was lost during the translation process.

Quantitative data analysis was conducted using the Statistical Package for the Social Sciences (SPSS), Version 21 (IBM Corp., Armonk, New York, USA). Mean overall pre- and post-session knowledge and positive intention scores were compared using a paired t-test at a 95\% confidence level. Intentions to practice early detection behaviours were analysed using descriptive statistics. Qualitative data from the focus group discussions were analysed using thematic synthesis in which data were organised into essential themes, thus providing a more holistic view of the programme. Thematic consistency was ensured through peer review and expert consultations.

Ethical approval for this study was granted by the Ethics Committee of the College of Nursing, SQU (\#SR/CON/MCHH/13/01). Informed consent was provided by all participants during the health education sessions. All women who wanted to take part in the health education sessions were allowed to participate, even if they subsequently chose not to complete the surveys or join the focus group discussions. Verbal consent to record the sessions and focus group discussions was given by all of the participants.

\section{Results}

Of the 53 participants, the majority were younger than 40 years old (83.0\%), were married (54.7\%), had been educated beyond the $12^{\text {th }}$ grade $(79.2 \%)$ and were employed (62.3\%) [Table 3]. A total of 30 women (56.6\%) participated in the pre- and post-session surveys to estimate the effectiveness of the health education programme as a tool to improve breast cancer awareness and knowledge. The overall mean knowledge score increased significantly following the health education session $(8.43 \pm 6.10$ versus $23.43 \pm 5.54 ; P<0.001)$. In addition, there was also a statistically significant increase in the women's mean scores regarding positive intentions to undertake early 
Table 3: Demographic and socioeconomic characteristics of Omani women participating in a breast cancer health education programme $(\mathrm{N}=53)$

\begin{tabular}{|c|c|}
\hline Characteristic & n (\%) \\
\hline \multicolumn{2}{|l|}{ Age in years } \\
\hline $20-29$ & $24(45.3)$ \\
\hline $30-39$ & $20(37.7)$ \\
\hline $40-49$ & $7(13.2)$ \\
\hline$\geq 50$ & $1(1.9)$ \\
\hline No response & $1(1.9)$ \\
\hline \multicolumn{2}{|l|}{ Nationality } \\
\hline Omani & $45(84.9)$ \\
\hline Other & $8(15.1)$ \\
\hline \multicolumn{2}{|l|}{ Marital status } \\
\hline Single & $24(45.3)$ \\
\hline Married & $29(54.7)$ \\
\hline \multicolumn{2}{|l|}{ Education level } \\
\hline Up to $12^{\text {th }}$ grade & $9(17.0)$ \\
\hline Beyond $12^{\text {th }}$ grade & $42(79.2)$ \\
\hline No response & $2(3.8)$ \\
\hline \multicolumn{2}{|l|}{ Employment status } \\
\hline Employed & $33(62.3)$ \\
\hline Unemployed & $19(35.8)$ \\
\hline No response & $1(1.9)$ \\
\hline \multicolumn{2}{|c|}{ Monthly income in OMR } \\
\hline$\leq 500$ & $2(3.8)$ \\
\hline $501-1,000$ & $22(41.5)$ \\
\hline $1,001-1,500$ & $7(13.2)$ \\
\hline $1,501-2,000$ & $2(3.8)$ \\
\hline $2,001-2,500$ & $3(5.7)$ \\
\hline$\geq 2,501$ & $9(17.0)$ \\
\hline No response & $8(15.1)$ \\
\hline
\end{tabular}

detection practices $(1.42 \pm 1.31$ versus $2.41 \pm 1.03$; $P<0.001)$ [Table 4].

Thematic analysis was undertaken of the feedback gathered from the health educators, research team, focus group discussions and audio recordings of the health education sessions. As a result of their experience and interactions with the participants, the health educators noted that the women appeared to have poor awareness of breast cancer signs and symptoms, risk factors and early detection practices. Nevertheless, the participants showed interest in
Table 4: Knowledge and positive intentions to undertake early detection practices before and after health education sessions among Omani women participating in a breast cancer health education programme $(\mathrm{N}=30)$

$\begin{array}{cccc}\text { Mean } & \text { Difference } & t & P \text { value }\end{array}$

Knowledge

Pre-session

$8.43 \pm 6.10 \quad 15.0$

Post-session $\quad 23.43 \pm 5.54$

$(12.2-17.8)$

$<0.001$

Positive intention

Pre-session $\quad 1.42 \pm 1.31$

Post-session $\quad 2.41 \pm 1.03$

$\stackrel{1.0}{(0.6-1.4)}$

4.71

$<0.001^{*}$

"Calculated using a non-parametric approach.

the sessions, were engaged during the different sections of the programme and were curious, active and unreserved during discussions, openly sharing their personal issues, stories, experiences and questions. Most women reported that they were satisfied with the sessions overall, but expressed a need for more interaction or discussion time. Table 5 provides a summary of the themes and feedback that emerged from the focus group discussions. In line with this feedback, the recommendations of the participants, health educators and the research team were used to modify the health education programme. Table 6 illustrates the outline of a modified health education programme which is more interactive and allows for more discussion and questions, moving away from the previous lecture-focused programme.

\section{Discussion}

According to the findings of the current study, the health education programme was found to significantly improve breast cancer knowledge scores among a cohort of Omani women. In addition, there was a significant increase in the number of women who intended to undertake early detection practices following the health education sessions. Based on the principles of the health promotion model, the programme was tailored to the individual characteristics, cultural values, behaviours and experiences of Muslim Omani women. ${ }^{27}$ By including certain tenets of motivational interviewing, the programme emphasised the integration of interpersonal and situational influences on the capacity of female Omanis to act positively for their own health, the intensification of their self-efficacy and empowerment and their intentions to detect breast cancer at an early stage and seek adequate breast health. ${ }^{33}$ As there is currently no official breast cancer screening programme in Oman, specific data on the use 
Table 5: Qualitative feedback from focus group discussions among selected Omani women following their participation in a breast cancer health education programme $(\mathrm{N}=30)$

\begin{tabular}{|c|c|c|}
\hline Theme & Issues & Challenges \\
\hline $\begin{array}{l}\text { Target audience } \\
\text { and location of the } \\
\text { health education } \\
\text { sessions }\end{array}$ & $\begin{array}{l}\text {-Sessions were conducted } \\
\text { in locations mostly } \\
\text { accessed by well-educated } \\
\text { and moderately high- } \\
\text { earning women }\end{array}$ & $\begin{array}{l}\text {-The participants were mostly } \\
\text { well-educated and belonged to } \\
\text { middle-income households } \\
\text {-There was little diversity in the } \\
\text { participant pool }\end{array}$ \\
\hline $\begin{array}{l}\text { Content of the } \\
\text { health education } \\
\text { sessions }\end{array}$ & $\begin{array}{l}\text { - The participants had } \\
\text { specific queries and } \\
\text { required clarifications } \\
\text { during sessions }\end{array}$ & $\begin{array}{l}\text {-Not all queries could be } \\
\text { answered by the health } \\
\text { educators, who were limited } \\
\text { for time and needed to stay on } \\
\text { topic and keep to the content of } \\
\text { the programme }\end{array}$ \\
\hline $\begin{array}{l}\text { Training of the } \\
\text { health educators }\end{array}$ & $\begin{array}{l}\text { - Health educators were } \\
\text { trained in basic breast } \\
\text { cancer knowledge and } \\
\text { public speaking skills }\end{array}$ & $\begin{array}{l}\text {-In a few instances, the health } \\
\text { educators were limited by their } \\
\text { lack of technical knowledge } \\
\text { or inadequate public speaking } \\
\text { skills }\end{array}$ \\
\hline $\begin{array}{l}\text { Learning strategies, } \\
\text { activities and } \\
\text { materials }\end{array}$ & $\cdot \mathrm{N} / \mathrm{A}$ & $\begin{array}{l}\text {-There were no "real-world" } \\
\text { stories from breast cancer } \\
\text { survivors } \\
\text {-The health educators did not } \\
\text { have formal religious training } \\
\text { and could not address certain } \\
\text { queries } \\
\text {-There was a lack of } \\
\text { summarised material/handouts } \\
\text { - The information on early } \\
\text { detection resources was } \\
\text { inadequate and too general } \\
\text {-There was not enough time } \\
\text { spent on tactile learning with } \\
\text { the breast model }\end{array}$ \\
\hline Attrition rate & $\begin{array}{l}\text { - The programme had a } \\
\text { high attrition rate as many } \\
\text { women were unable to stay } \\
\text { for the entire session or left } \\
\text { before the post-session test }\end{array}$ & $\begin{array}{l}\text { - The target audience of the } \\
\text { sessions consisted primarily of } \\
\text { walk-ins } \\
\text { - Many women had prior } \\
\text { commitments and left when } \\
\text { the sessions went over the } \\
\text { time limit }\end{array}$ \\
\hline Mode of delivery & $\begin{array}{l}\text { The sessions relied } \\
\text { heavily on multimedia } \\
\text { presentation slides and } \\
\text { lectures }\end{array}$ & $\begin{array}{l}\text {-The structure of the } \\
\text { sessions was found to be } \\
\text { overly restrictive and did not } \\
\text { allow enough time for open } \\
\text { discussion } \\
\text {-Discussion topics did not } \\
\text { include discussion of breast } \\
\text { health resources in Oman }\end{array}$ \\
\hline
\end{tabular}

$\begin{array}{ll}\text { Positives } & \text { Feedback } \\ \text {-None } & \text { Future sessions should be conducted at more } \\ & \text { diverse locations in order to be accessible to } \\ \text { women from lower socioeconomic and less } \\ \text { educated backgrounds }\end{array}$

- The health educators were able to deal with most queries

- Health educators should be trained in more detail regarding aspects of breast cancer, breast health service delivery and early detection resources specific to the Omani healthcare system

- The level of knowledge of the health educators was nevertheless appreciated by participants

- The participants appreciated many of the learning strategies, including the 'myth or fact' game, the open discussions and the use of images and the breast model as learning strategies

None

- The interactive components of the sessions were appreciated, as they allowed for conversation and gave importance to participants' personal experiences
- Health educators should be trained to improve their technical knowledge of breast cancer, disease stages, treatment modalities and treatment concerns

-Additional training in public speaking should also be conducted

- Future sessions should involve breast cancer survivors who can talk about their experiences and motivate the participants

- Future sessions should include a discussion on the responsibility of Muslims towards their own health and self-care

-Future sessions should provide pamphlets with summarised session information, including additional specific information on early detection resources in Oman

-At the end of future sessions, a token gift should be given to participants in gratitude of their participation and to act as a memento/reminder of the sessions

-The venue of future sessions should be made more convenient/specific to the session -Publicity tactics and duration for future sessions should be improved persuaded and motivated to remain present throughout the entire session - Tangible incentives should be provided to participants at the end of future sessions

- To allow for more flexibility, future sessions should focus on interactive discussions with presentation slides as minor learning aids -Future sessions should incorporate "real life" stories and personal experiences to enhance interaction and accessibility of the material -In future sessions, participants should be of screening methods such as mammography services are not readily available due to the voluntary nature of mammograms and clinical breast examinations; thus, it was impossible to compare the findings of the current study with any baseline use of these services in Oman.

In the current study, feedback from the participants, health educators and research team indicated certain modifications to the health education programme which might improve its effectiveness in increasing breast cancer awareness in Oman. Based on these recommendations, the improved programme would need to target a larger sample of women, including those who belong to lower socioeconomic and less educated backgrounds. In addition, the participants should be motivated to remain for the entire session, as well as participate more actively in any associated education or research activities. The health education programme should also incorporate answers to questions raised during the sessions and health educators should undergo more rigorous training in technical breast cancer knowledge and public speaking. Novel learning strategies and activities were recommended such as the use of relatable "real life" stories and the inclusion of actual breast cancer survivors and religious experts in the sessions. In 
Table 6: Outline of a modified health education programme for future use based on improvements gathered from feedback from health educators, participants and the research team

\begin{tabular}{|c|c|c|}
\hline Section & Content & Learning strategy \\
\hline "Real life" story & $\begin{array}{l}\text {-An incomplete story describing a young Omani woman } \\
\text { who discovers changes in her breast, in which the } \\
\text { participants are encouraged to finish the story themselves } \\
\text { - The character is named "Amal" which means hope } \\
\text { - The sociodemographic features of the character are } \\
\text { consistent with the majority of breast cancer cases in Oman } \\
\text { (i.e. young and married with children and with a family } \\
\text { history of breast cancer) }\end{array}$ & $\begin{array}{l}\text {-Participants are encouraged to empathise with Amal } \\
\text { - Discussion of how each participant would complete the story }\end{array}$ \\
\hline Introduction & $\begin{array}{l}\text {-What do you associate with the term "breast cancer"? } \\
\text {-What prior knowledge do you have about breast cancer? } \\
\text {-Introduction to breast cancer with definitions and global/ } \\
\text { local statistics } \\
\text {-Emphasis on the fact that breast cancer can be cured if } \\
\text { detected early }\end{array}$ & $\begin{array}{l}\text {-Discussion of associations with the term "breast cancer" } \\
\text { - Discussion of prior knowledge of breast cancer } \\
\text {-Pictographs depicting facts, definitions and statistics about } \\
\text { breast cancer }\end{array}$ \\
\hline $\begin{array}{l}\text { Breast cancer signs } \\
\text { and symptoms }\end{array}$ & $\begin{array}{l}\text {-What breast cancer signs and symptoms are you aware of? } \\
\text {-Illustration of signs and symptoms } \\
\text {-Emphasis on "knowing your own breasts" to identify } \\
\text { abnormalities }\end{array}$ & $\begin{array}{l}\text {-Discussion of one sign/symptom of breast cancer that each } \\
\text { participant may be aware of } \\
\text {-Multimedia presentation slides to illustrate the various } \\
\text { signs and symptoms of breast cancer }\end{array}$ \\
\hline $\begin{array}{l}\text { Risk factors for breast } \\
\text { cancer }\end{array}$ & $\begin{array}{l}\text {-What are the factors that make some women more } \\
\text { vulnerable to breast cancer than others? } \\
\text {-What are some healthy habits that can reduce your breast } \\
\text { cancer risk? } \\
\text {-Emphasis on a generally healthy lifestyle }\end{array}$ & $\begin{array}{l}\text {-Discussion of one risk factor of breast cancer that each } \\
\text { participant may be aware of } \\
\text {-Discussion of breast cancer facts, myths/misconceptions } \\
\text { and known risk factors } \\
\text { - Multimedia presentation slides to illustrate known risk } \\
\text { factors as a retention aid } \\
\text {-Discussion of healthy habits and preventative measures to } \\
\text { reduce breast cancer risk }\end{array}$ \\
\hline $\begin{array}{l}\text { Early detection and } \\
\text { screening practices }\end{array}$ & $\begin{array}{l}\text {-What measures can you take to detect breast cancer early? } \\
\text {-Emphasis on "knowing your own breasts" to identify } \\
\text { abnormalities } \\
\text {-What are the health responsibilities of Muslims? }\end{array}$ & $\begin{array}{l}\text {-Discussion of each early detection practice (e.g. BSE, CBE } \\
\text { and mammograms) and the importance of being familiar } \\
\text { with one's own breasts } \\
\text {-Discussion of Muslims' responsibility towards their own health } \\
\text { - Extension of Amal's story to relate a scenario in which } \\
\text { Amal visits the doctor and is referred for mammography } \\
\text { services }\end{array}$ \\
\hline $\begin{array}{l}\text { Pledge to promote } \\
\text { breast health }\end{array}$ & $\begin{array}{l}\text { - Encourage participants to sign a pledge of commitment } \\
\text { to healthy practices and breast health awareness with } \\
\text { accompanying tokens/mementoes of the programme (e.g. } \\
\text { pink ribbons) }\end{array}$ & $\begin{array}{l}\text { - Recitation of pledge in unison } \\
\text { - Signing of pledge } \\
\text { - Distribution of tokens/mementoes as positive reinforcement }\end{array}$ \\
\hline
\end{tabular}

$B S E=$ breast self-examination $; C B E=$ clinical breast examination .

addition, other strategies for future health education sessions include the use of a breast model to teach comprehensive breast self-examination techniques, dissemination of information on local breast cancer screening facilities in Oman and distribution of physical tokens/mementoes to remind participants of their pledge to maintain and promote breast health.

In the new health education programme, an emphasis on participant interaction would improve the fidelity of the programme content to the original ESRA breast cancer model, which is based on empowerment through awareness and identifies the main barriers present within three enabling systems. ${ }^{6}$ As women were the target population in the current study, the previous health education programme was able to extensively address cultural/religious/fatalistic barriers, although factors related to the personal/familial/environmental and healthcare-related systems were addressed only to a limited extent. It is recommended that the future health education programme involve stakeholders related to these two enabling systems, including family members, men, religious leaders and healthcare professionals, in order to enable these systems to support breast cancer awareness and early detection practices in Oman. Moreover, as this study measured only the immediate effects of a health education programme on breast cancer awareness, future studies should evaluate long-term behavioural effects. This is due to the fact that any changes in factors related to the three enabling systems-such as changes in personal beliefs, cultural values, social taboos and interpersonal relationships along with systematic improvements in breast health resources in Oman-would take place over time. As such, collecting evidence soon after the implementation of a health education programme would not provide an accurate depiction of its effects.

Despite the encouraging results of the present study, caution should be exercised before generalising the results to the Omani community as a whole. The study design relied on a convenience sampling method to recruit participants from three specific locations, since previous experience with random sampling in 
this topic has led to high attrition rates. This resulted in a cohort whom were primarily $20-39$ years old and either regularly accessed or visited fitness clubs or were intending to become regular members. As such, the majority of the study sample were relatively more affluent and educated than the general population of Oman.

\section{Conclusion}

Breast cancer is a global healthcare challenge and there is a need to improve awareness and early breast cancer detection practices. In the current study, a culturallytailored breast cancer health education programme was developed based on a previously described model. The programme was found to significantly increase breast cancer awareness and positive intentions to undertake early detection practices among a cohort of Omani women. Recommendations arising from feedback obtained from the health education sessions may be used to revise and improve the structure, content and delivery of the programme in the future. However, long-term behavioural outcomes need to be evaluated to ensure the effectiveness of this modified programme in promoting breast health among Omani women.

\section{CONFLICT OF INTEREST}

The authors declare no conflicts of interest.

\section{FUNDING}

This study was funded by a grant from His Majesty Sultan Qaboos as part of the Strategic Research Fund, Muscat, Oman (\#SR/CON/MCHH/13/01).

\section{References}

1. World Health Organization. Breast cancer: Prevention and control. From: www.who.int/cancer/detection/breastcancer/ en/index1.html Accessed: Oct 2016.

2. International Agency for Research on Cancer, World Health Organization. All cancers (excluding non-melanoma skin cancer): Estimated incidence, mortality and prevalence worldwide in 2012. From: globocan.iarc.fr/Pages/fact_sheets_ cancer.aspx Accessed: Oct 2016.

3. Kumar S, Burney IA, Al-Ajmi A, Al-Moundhri MS. Changing trends of breast cancer survival in Sultanate of Oman. J Oncol 2011; 2011:316243. doi: 10.1155/2011/316243.

4. Al-Moundhri M, Al-Bahrani B, Pervez I, Ganguly SS, Nirmala V, Al-Madhani A, et al. The outcome of treatment of breast cancer in a developing country: Oman. Breast 2004; 13:139-45. doi: 10.1016/j.breast.2003.10.001.

5. Al-Azri M, Al-Awisi H, Al-Rasbi S, El-Shafie K, Al-Hinai M, Al-Habsi $\mathrm{H}$, et al. Psychosocial impact of breast cancer diagnosis among Omani women. Oman Med J 2014; 29:437-44. doi: 10.5001/omj.2014.115.
6. Alkhasawneh E, Siddiqui ST, Leocadio M, Seshan V, Al-Farsi Y, Al-Moundhri MS. I do not even say "it": A mixed methods study on breast cancer awareness of Omani women. Asian Pac J Cancer Prev 2016; 17:2247-54. doi: 10.7314/APJCP. 2016.17.4.2247.

7. Donnelly TT, Al Khater AH, Al-Bader SB, Al Kuwari MG, Al-Meer N, Malik M, et al. Beliefs and attitudes about breast cancer and screening practices among Arab women living in Qatar: A cross-sectional study. BMC Womens Health 2013; 13:49. doi: 10.1186/1472-6874-13-49.

8. Radi SM. Breast cancer awareness among Saudi females in Jeddah. Asian Pac J Cancer Prev 2013; 14:4307-12. doi: 10.7314/APJCP.2013.14.7.4307.

9. Alkhasawneh IM. Knowledge and practice of breast cancer screening among Jordanian women. Oncol Nurs Forum 2007; 34:1211-17. doi: 10.1188/07.ONF.1211-1217.

10. Alkhasawneh IM, Akhu-Zaheya LM, Suleiman SM. Jordanian nurses' knowledge and practice of breast self-examination. J Adv Nurs 2009; 65:412-16. doi: 10.1111/j.1365-2648.2008.04891.x.

11. Parsa P, Kandiah M, Abdul Rahman H, Zulkefli NM. Barriers for breast cancer screening among Asian women: A mini literature review. Asian Pac J Cancer Prev 2006; 7:509-14.

12. Islam RM, Bell RJ, Billah B, Hossain MB, Davis SR. Awareness of breast cancer and barriers to breast screening uptake in Bangladesh: A population based survey. Maturitas 2016; 84:68-74. doi: 10.1016/j.maturitas.2015.11.002.

13. Ramathuba DU, Ratshirumbi CT, Mashamba TM. Knowledge, attitudes and practices toward breast cancer screening in a rural South African community. Curationis 2015; 38:1-8. doi: 10.4102/curationis.v38i1.1172.

14. Gangane N, Anshu, Manvatkar S, Ng N, Hurtig AK, San Sebastián M. Prevalence and risk factors for patient delay among women with breast cancer in rural India. Asia Pac J Public Health 2016; 28:72-82. doi: 10.1177/1010539515620630.

15. Yip $\mathrm{CH}$, Buccimazza I, Hartman M, Deo VS, Cheung PS. Improving outcomes in breast cancer for low and middle income countries. World J Surg 2015; 39:686-92. doi: 10.1007/ s00268-014-2859-6.

16. Othman AK, Kiviniemi MT, Wu YW, Lally RM. Influence of demographic factors, knowledge, and beliefs on Jordanian women's intention to undergo mammography screening. J Nurs Scholarsh 2012; 44:19-26. doi: 10.1111/j.1547-5069. 2011.01435.x.

17. Othman A, Ahram M, Obeidat RF, Obeidat N, Al-Tarawneh MR. Barriers for mammography among non-adherent women in Jordan: A national survey. Life Sci J 2013; 10:2268-74.

18. Ramos AK, Correa A, Trinidad N. Perspectives on breast health education and services among recent Hispanic immigrant women in the Midwest: A qualitative study in Lancaster County, Nebraska. J Cancer Educ 2016; 31:666-72. doi: 10.10 07/s13187-015-0886-0.

19. Shirazi M, Bloom J, Shirazi A, Popal R. Afghan immigrant women's knowledge and behaviors around breast cancer screening. Psychooncology 2013; 22:1705-17. doi: 10.1002/ pon.3216.

20. Bickell NA, Weidmann J, Fei K, Lin JJ, Leventhal H. Underuse of breast cancer adjuvant treatment: Patient knowledge, beliefs, and medical mistrust. J Clin Oncol 2009; 27:5160-7. doi: 10.12 00/JCO.2009.22.9773.

21. Hall CP, Wimberley PD, Hall JD, Pfriemer JT, Hubbard EM, Stacy AS, et al. Teaching breast cancer screening to African American women in the Arkansas Mississippi River Delta. Oncol Nurs Forum 2005; 32:857-63. doi: 10.1188/05.ONF. 857-863. 
22. Kline KN. Cultural sensitivity and health promotion: Assessing breast cancer education pamphlets designed for African American women. Health Commun 2007; 21:85-96. doi: 10.10 80/10410230701283454.

23. Ouyang $\mathrm{YQ}, \mathrm{Hu} \mathrm{X}$. The effect of breast cancer health education on the knowledge, attitudes, and practice: A community health center catchment area. JCancer Educ 2014; 29:375-81. doi: 10.10 07/s13187-014-0622-1.

24. Gandeh BS, Milaat WA. Effect of a breast cancer health education program on the awareness and practice of Jeddah female secondary school students. J Family Community Med 2000; 7:31-6.

25. Abd El Aziz HM, Akl OA, Ibrahim HK. Impact of a health education intervention program about breast cancer among women in a semi-urban area in Alexandria, Egypt. J Egypt Public Health Assoc 2009; 84:219-43.

26. Rezaeian M, Sharifirad G, Mostafavi F, Moodi M, Abbasi MH. The effects of breast cancer educational intervention on knowledge and health beliefs of women 40 years and older, Isfahan, Iran. J Educ Health Promot 2014; 3:43. doi: 10.41 03/2277-9531.131929.

27. Pender NJ, Murdaugh CL, Parsons MA. Health Promotion in Nursing Practice, 6th ed. Upper Saddle River, New Jersey, USA: Pearson, 2010. Pp. 250-355.
28. World Education Health Literacy Special Collection. Health education and adult literacy: Breast \& cervical cancer HEAL:BCC Curriculum. From: http://healthliteracy.worlded. org/heal/healBccHtml/index.htm Accessed: Oct 2016.

29. John Snow Inc. JSI adolescent breast cancer curriculum. From: www.jsi.com/JSIInternet/Inc/Common/_download_pub. cfm?id=11148\&lid=3 Accessed: Oct 2016

30. Roberts NJ, Ghiassi R, Partridge MR. Health literacy in COPD. Int J Chron Obstruct Pulmon Dis 2008; 3:499-507. doi: 10.21 47/COPD.S1088.

31. Stubbings S, Robb K, Waller J, Ramirez A, Austoker J, Macleod U, et al. Development of a measurement tool to assess public awareness of cancer. Br J Cancer 2009; 101:S13-7. doi: 10.1038/ sj.bjc. 6605385

32. Al-Khasawneh EM, Leocadio M, Seshan V, Siddiqui ST, Khan AN, Al-Manaseer MM. Transcultural adaptation of the Breast Cancer Awareness Measure. Int Nurs Rev 2016; 63:445-54. doi: 10.1111/inr.12265.

33. Miller WR, Rollnick S. Motivational Interviewing: Preparing people for change, 2nd ed. New York, USA: Guilford Press, 2002. Pp. 305-414. 